\title{
Barriers and enablers to learning during team-based clinical simulations: Reflective interviews with final year undergraduate nursing students
}

\author{
Jacinta Dzioba ${ }^{1}$, Robyn Cant ${ }^{1}$, Simon Cooper ${ }^{1,2,3}$, Fiona Bogossian ${ }^{4}$, Nicole M. Phillips ${ }^{5}$ \\ 1. School of Nursing and Midwifery, Monash University, Berwick, Victoria, Australia. 2. University of Brighton, UK. 3. The \\ University of Hong Kong, China. 4. School of Nursing and Midwifery, The University of Queensland, Brisbane, QId, Australia. \\ 5. School of Nursing and Midwifery, Deakin University, Melbourne: Burwood Campus, Victoria, Australia.
}

Correspondence: Robyn Cant. Address: Monash University, 100 Clyde Road, Berwick, Victoria, Australia. Email: robyn.cant@monash.edu

Received: March 31, 2014

DOI : $10.5430 /$ jnep.v4n10p32

\author{
Accepted: July 15, 2014 \\ Online Published: August 4, 2014 \\ URL: http://dx.doi.org/10.5430/jnep.v4n10p32
}

\section{Abstract}

Background: Contemporary approaches to clinical simulation can enhance educational outcomes. However, simulation approaches do have limitations with possible compromises for learning and teaching. This paper aims to identify barriers and enablers to learning in simulated clinical settings.

Methods: A generic qualitative design was applied. Semi-structured group video debriefing interviews were held with Australian final-year nursing students who completed three patient deterioration scenarios with a standardized patient. Audio-recorded interviews were transcribed and analysed to identify emergent themes.

Results: Interviews with 15 teams of three students $(n=45)$ from three universities were analysed. Learning enablers were 'Realism of the simulated environment'; 'Practicing: we should do this at uni'; 'Learning from reflection and expert feedback', and 'How to become competent: know the gaps'. Barriers to learning included 'Increased stress from inexperience; 'Expectations when pretending' and 'Lack of assistance'. Skills practice in team-based settings with applicable reflection and debriefing was regarded as beneficial. Simulated patients enhanced fidelity but were unable to replicate actual clinical signs. High stress levels were perceived as a barrier to learning.

Conclusions: Applicably designed high fidelity simulations with video-based reflective review offer repeated rehearsal of clinical situations to enable learning. This educational strategy may reduce the time it takes undergraduate students to reach competency.

\section{Key words}

Experiential learning, High-fidelity simulation, Students, Nursing, Patient deterioration

\section{I ntroduction}

Human simulation is a core contemporary approach to learning in undergraduate nursing education. Simulation can replicate many essential aspects of a clinical situation, enabling students to practice in a safe environment and prepare for their professional life ${ }^{[1,2]}$. Simulation-based education approaches are effective in improving nursing knowledge ${ }^{[3,4]}$ and 
critical thinking ${ }^{[5,6]}$, both in the short and longer-term ${ }^{[7]}$. The aim of simulation is: 'to replicate some or nearly all of the essential aspects of a clinical situation so that the situation may be more readily understood and managed when it occurs for real in clinical practice, ${ }^{[8: \mathrm{p} 3]}$.

A key feature of simulation education is that it enables students to consolidate learning through an interactive educational process ${ }^{[9]}$. There are three core components for effective simulation education: a pre-briefing, the simulation exercise, and a post-debriefing ${ }^{[10]}$. Reflectivity during debriefing is thought to be one of the most important factors influencing learning ${ }^{[11,12]}$ and is achieved through peer or instructor feedback, or reflective video review of performance ${ }^{[13]}$. This enables integration of knowledge and skills ${ }^{[14]}$ and improves confidence ${ }^{[15]}$. Importantly, simulation approaches enable repetitive practice and integration of knowledge and clinical skills in a safe environment without risk to real patients ${ }^{[16]}$.

The purpose of this paper is to report on nursing students' simulation experience in patient deterioration scenarios, focusing on the barriers and enablers related to learning. The study reported here was embedded in a larger project that ultimately produced a web-based e-Simulation interactive teaching resource (FIRST2ACTWeb.com). Details of the project protocol are published ${ }^{[17]}$ as are student performance outcomes ${ }^{[18]}$.

\section{Methods}

Using a generic qualitative descriptive design ${ }^{[19]}$ this report utilises qualitative data from student group interviews conducted during debriefing in a simulation education program.

\subsection{Participant recruitment}

A total of 97 students were recruited from three Australian universities collaborating in the broader research. Eligible participants were final year nursing students (third or fourth year) who had completed an 'acute care' unit of study.

\subsection{Simulation overview}

All participants completed three consecutive video-recorded high fidelity simulation scenarios. A professional actor played a simulated patient in a ward-like setting and a staff member played the role of a newly qualified inexperienced doctor. This individual reported vital sign outcomes (following measurement on the actor), but did not prompt students. Students were grouped into teams of three and randomly rotated into the nurse leadership role for each of three 8-minute scenarios. Scenarios were based on common patient presenting conditions: acute myocardial infarction, shock and chronic obstructive pulmonary disease. On completion, teams attended a debriefing interview with a clinical faculty member during which the videoed simulations were used to assist recall and to discuss performance and educational outcomes; a process known as photo-elicitation ${ }^{[20]}$.

\subsection{Data collection}

Debriefing interviews involving photo-elicitation were conducted with each student team by a member of the research team. A semi-structured questioning format was used to enhance data consistency, commencing with open questions such as 'How do you think it went?' and 'What have you learnt from this experience? The interviews averaged 40 minutes duration and the interviews were audio recorded and fully transcribed.

\subsection{Analysis}

Thematic analysis conducted using an inductive approach to coding provided the theoretical framework and enabled identified themes to be data driven ${ }^{[21]}$. An audit trail was documented at each step ${ }^{[22]}$. Transcripts were read and re-read by the primary author to highlight key words associated with learning from simulation and these were used as nominal codes. The identified codes were tabulated as a theme together with related quotations and additional sub-themes were clustered under each code. After reviewing five interviews from each University (total 15), data saturation was apparent. In a final 
synthesis stage, two main themes and 27 sub-themes were mapped to identify links between each. Discussions were then held between two researchers who subsequently reviewed, revised and confirmed the main themes to reach consensus. This synthesis resulted in four sub-themes that enabled learning and three sub-themes that represented barriers.

\subsection{Ethical considerations}

Ethical approval was granted by all three participating universities prior to data collection. All students voluntarily consented to participate in the study.

\section{Results}

In total, 97 final year nursing students from three universities completed the simulation program in groups of three and gave feedback in debriefing interviews. (Two groups comprised two students: $n=33$ groups) Participants were predominantly female (93\%) and the overall median age was 21 years.

Two core themes emerged: (i) Enablers of simulation learning and (ii) Barriers to learning during simulation. Four enabling sub-themes were: 'Realism of the simulated environment'; 'Practising -we should do this at uni'; 'Learning from reflection and expert feedback' and 'How to become competent: know the gaps'. The three barrier-related sub-themes were: 'Increased stress from inexperience'; 'Role expectations when pretending' and 'Lack of assistance'. Each of these is described below, with groups identified by university (A, B or C) and by group interview number e.g. (A5).

\subsection{Enablers: facilitation of learning through simulation events}

The debriefing discussions focused upon simulation in general, the use of a human actor, clinical practice, reflection, and competency issues. Many of these acted as enablers to facilitate the students' learning.

\subsubsection{Theme 1: Realism of the simulated environment}

Participants described factors that influenced the fidelity (believability) of the scenarios. Fidelity was enhanced by the ward-like setting, applicable documentation of records and by the human patient. All of these were seen as mimicking the real world. Nearly every group commented on the presence of a human patient actor and how this enhanced the realism of the case.

He was quite a good actor. And at that point, you almost believe it’s real. (A5)

... he was very believable ...whereas: saying 'this dummy has shortness of breath', you don't know how severe it is. (A5)

\subsubsection{Theme 2: Practising: - we should do this at uni}

Participants described role-playing as a positive experience. They saw simulation as enabling both immersion in a 'medical situation' and also as preparation for a new clinical situation in future.

...I don't think you can get enough experience like that ...I think it's really beneficial, especially that we're nearly graduating. (B10)

...I think it was good ...you know, actually [to] get put in the situations. (B3)

Many felt they would benefit from more practices using a simulation technique.

We should do this at uni ...seriously, it’s good. (B3)

The involvement of student teams in scenarios facilitated problem-solving by allowing students to resolve issues collaboratively with their peers. 
I think it felt better to work as a team ...more reassuring ...more brains. (C3)

...you don't panic as much if you have someone else there. (A5)

By the end of it, you were quite good ... as we went into each one we got a bit more confident. (C10)

Thus participants felt there were benefits of repeated practice.

\subsubsection{Theme 3: Learning from reflection and expert feedback}

Reflectivity was apparent during the post-scenario period. Self-reflection occurred immediately after a scenario, and reflection on the group's performance was evident during playback to the team of recorded footage and in general group discussion. The students displayed insight into their practice but tended to overemphasise negative aspects of their performance:

...when I came out of my scenario, I just thought 'I could've done this' and 'I could've done that', 'I could've done this better'. (A1)

Further, the replay of video footage enhanced their reflection:

I'm glad that we got to do it and watch it; it makes me think about what you do. (C3)

-.on reviewing this, I actually probably should have taken the ECG first. (C4)

Reflection also occurred through shared discussion between team members:

We've really learned so much from just sitting outside and debriefing. (C1)

The participatory reflective process enabled individuals to query their practice, and to identify gaps in their knowledge.

\subsubsection{Theme 4: How to become competent: know the gaps}

Participants reported that they had learned from the simulation experiences acknowledging that nursing tasks were more than a paper-based activity:

[I felt] very incompetent ... I'm going home to read my textbooks. (A7)

[I] learnt so much, how to manage situations and be more organized. (B1)

\subsection{Barriers to learning during simulation events}

Throughout the debriefing sessions, students also described barriers to learning.

\subsubsection{Theme 1: I ncreased stress from inexperience}

Students described various issues that were seen as contributing to personal stress during the simulations. These included feelings of panic owing to psychological pressure and uncertainty, especially comprehending the importance of correct decision-making regarding a 'real' patient.

We were a bit hesitant to say things as well, because we weren't really sure whether it was going to be right or wrong. (A7)

In addition environmental factors such as staff observers, a camera and a lack of immediate assistance raised concerns.

...it was not realistic when you first went in ...out on the ward you don’t have someone sitting there watching everything you do. (C3)

Furthermore, students were very aware of their lack of clinical experience. 
[I was stressed because] I didn't know the answers... what was wrong with him or how to fix it, and there was a camera. (A3)

I think we need a bit more education so that we can feel more confident in what we're doing. (A3)

\subsubsection{Theme 2: Role expectations when pretending}

Participants were unsure what tasks they were required to perform and which they should pretend to do in the role-play. For example there was confusion when recording patient observations (as participants were required to take, for example, a blood pressure but ask the staff observer for the result). Students described this dilemma.

....are we pretending or are we actually doing it? (C3)

Thus the simulation exercise did not fully replicate a nursing role in real life.

\subsubsection{Theme 3: Lack of assistance}

As the patient deteriorated, participants described their frustration at the lack of assistance despite their call for the 'crash cart', a Medical Emergency Team, a doctor, or help from experienced nurses.

...I don't like it when I don't know what I'm doing, or if I don't know what to do or if there's no one we can ask questions of. (A3)

..like if we were in a real hospital ...we would have people rush [in] and the crash cart would be there. (A3)

\section{Discussion}

This study highlighted nursing students' perceptions of both enablers and barriers to learning in a high fidelity simulated learning environment. Enablers included the highly believable human patient actors and close representation of scenarios to clinical reality. Practising skills in a holistic and safe setting with the help of other peers as team members was seen as highly beneficial. Debriefing with video review was perceived to enhance participants' reflection at a number of levels with benefit to learning outcomes. Furthermore, repeated practice of clinical skills over three scenarios did improve ratings of performance ${ }^{[18]}$ and was seen as enhancing application of theoretical knowledge and enabling participants to identify competency gaps to learn from errors. This is consistent with findings from Helyar et al. ${ }^{[23]}$ who described learning from errors as a powerful educational experience.

Participants also identified a number of barriers to learning including high levels of stress. One reason given for this was uncertainty about how far role-play should extend when acting out a pretend situation. Achieving a suitable level of believability presents a design dilemma in simulation education, for students may not be able to transcend all aspects to perceive role-play as being real. For example, the environment and engineering of the simulation may be considered high fidelity and therefore real, while psychological realism, ‘the participant's perception of the simulation realism' may not be perceived as genuine ${ }^{\text {[23: } \mathrm{p} 12]}$.

It is likely that infrequently occurring acute patient deterioration events do induce high levels of stress and it is thus important to mirror this in the educational setting. When designing the scenarios, the research team deliberately built in factors such as time limitations and inadequate medical assistance to mirror a primary responder situation. A number of studies indicate gender differences in the management of stress- females being particularly sensitive to stressful events ${ }^{[24]}$. In urgent situations stress enhances performance but reaches a peak when anxiety becomes too high, leading to a decrease in performance. This is described as an inverted $U$ shaped relationship between stress and learning, with performance optimised at moderate levels of stress ${ }^{[25]}$. Further, Laseter ${ }^{[26]}$ reports the "paradox of anxious and stupid feelings, yet increased awareness" (p. 272), suggesting that anxiety enhances situation awareness although it may decrease confidence. Educationally, therefore, an optimal balance is required between applicable challenge and maximal learning. In simulation 
this may be achieved by, for example, allowing 'time out' or through supportive feedback. However the latter is dependent on the objectives of the simulation which may be designed as an experiential learning opportunity, an opportunity for formative assessment 'for' learning, or for a summative assessment 'of' learning.

While the use of human simulated patients enhances overall fidelity, humans cannot be 'programmed' to simulate the required physiology or vital signs. This limitation causes some confusion, as participants are required to record vital signs but received the 'results' verbally from a 'tutor'. Further, scenarios that include non-expert assistance are appropriate in order to standardise the experience/assessment as well as to mimic clinical situations where assistance is limited. However this approach does cause students some frustration and will need explanation in the debriefing phases.

In this study students had previously been taught the fundamentals of patient deterioration management as part of the curriculum, however in these three simulated situations performance ratings showed a deficit in knowledge and skills ${ }^{[18]}$. A qualifying factor, however, was that over half of the participants had had no previous clinical exposure to the acute conditions depicted in the scenarios. Studies have shown that high-fidelity simulation exercises enable students to link theoretical concepts, clinical skills and critical thinking with their practice thereby developing expertise ${ }^{\text {[27] }}$. The findings from this study suggest that high fidelity simulation is acceptable and welcomed by students who reported enhanced clinical skills developed from the simulation and video debriefing. Furthermore, the results appear to confirm that reflective debriefing has a key influence on learning, as has been described in other studies ${ }^{[11-15]}$.

\section{A concept model}

Repeated application of simulation practice is reported to be essential to reduce the time it takes undergraduates to reach competency ${ }^{[28]}$. Figure 1 illustrates a conceptual model of high fidelity team-based simulation that emerged from the thematic findings of this study. This illustrates the interrelationship between the key elements of learning (simulation, reflection and feedback) and the factors that influence outcomes: fidelity, teamwork, and practice/experience. In the right combination, these elements will enhance confidence and competence. The concept model is proposed as a tool for use when planning simulation tasks for students. Educators need to consider how fidelity, teamwork and the practice/ experience will benefit the student's learning outcomes with the need to include reflective activities to increase the learner's competence and confidence.

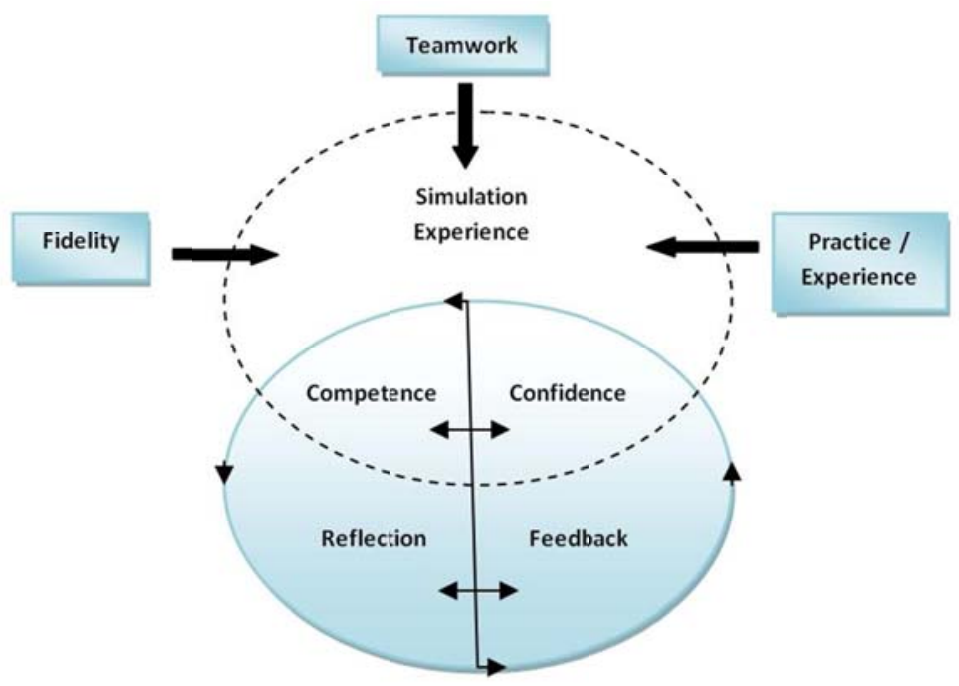

Figure 1. A concept model of high fidelity team based simulation education

As with all qualitative studies, the findings rely on interpretation of data by researchers and the results may be subject to bias. The findings may therefore not apply to all nursing students. However, two researchers applied valid qualitative 
analysis strategies and achieved consensus about the narrative themes. The results therefore affirm the use of simulation using human patient actors and peer-based team practices in undergraduate simulation education.

\section{Conclusion}

Barriers as well as enablers to learning were identified by participants in team-based simulation education. Overall, the simulation exercises, reflection and feedback outcomes were influenced by the fidelity, teamworking, and experience provided through repeated practice. Participants valued the skills practice in team-based simulations and regarded video-assisted debriefing with an expert as assisting their reflection. For some individuals, however, high stress levels may reduce the effectiveness of teaching and learning. Standardized patients (human actors) enhance simulation fidelity and aid learning in simulation education but present limitations regarding the true replication of clinical signs. High fidelity simulation with video-based reflective review is beneficial as it can offer repeated rehearsal of clinical skills and may reduce the time it takes for students to reach competency.

\section{Conflict of interest}

There authors declare there is no conflict of interest.

\section{Acknowledgements}

Support for the original work was provided by the Australian Learning and Teaching Council Ltd, an initiative of the Australian Government Department of Education, Employment and Workplace Relations. The authors wish to acknowledge the contribution of other members of the FIRST2ACT project team: Alison Beauchamp, Tracey Bucknall, Brett DeVries, Ruth Endacott, Helen Forbes, Victoria Kain, Lisa McKenna, Leigh Kinsman, Joanne Porter and Susan Young.

\section{References}

[1] Motola I, Devine L, Chung H, Sullivan J, Issenberg B. Simulation in healthcare education: A best evidence practical guide. AMEE Guide No. 82. Medical Teacher. 2013; 35: e1511-e1530.

[2] Hovancsek M. Using simulation in nurse education. In Jeffries, P.R. (ed.), Simulation in nursing education; from conceptualization to evaluation. (pp 1-9) New York: National League for Nursing, 2007.

[3] Alinier G, Hunt B, Gordon R, Harwood C. Effectiveness of intermediate-fidelity simulation training technology in undergraduate nursing education. Journal of Advanced Nursing. 2006; 54: 359-369. PMid:16629920

http://dx.doi.org/10.1111/j.1365-2648.2006.03810.x

[4] Brannan J, White A, Bezanson J. Simulator effects on cognitive skills and confidence levels. Journal of Nursing Education. 2008; 47: 495-500. PMid:19010047 http://dx.doi.org/10.3928/01484834-20081101-01

[5] Lewis R, Strachan A, McKenzie Smith M. Is high fidelity simulation the most effective method for the development of non-technical skills in nursing? A review of the current evidence. The Open Nursing Journal. 2012; 6: 82-89. PMid:22893783 http://dx.doi.org/10.2174/1874434601206010082

[6] Shepherd IA, Kelly CM, Skene FM, White KT. Enhancing graduate nurses' health assessment knowledge and skills using low-fidelity adult human simulation. Simulation in Healthcare. 2007; 2(1): 16-24. PMid:19088604 http://dx.doi.org/10.1097/SIH.0b013e318030c8dd

[7] Ruggenberg S. The effect of simulated clinical experience on knowledge, near transfer, and far transfer in nursing education. (Thesis). University of San Francisco, California: 2008.

[8] Hravnak M, Beach M, Tuite P. Simulator technology as a tool for education in cardiac care Journal of Cardiovascular Nursing. 2007; 22: 16. PMid:17224693 http://dx.doi.org/10.1097/00005082-200701000-00003

[9] Kardong-Edgren SE, Starkweather AR, Ward LD. The integration of simulation into a clinical foundations of nursing course: Student and faculty perspectives. International Journal of Nursing Education Scholarship. 2008; 5: 1. PMid:18673294 http://dx.doi.org/10.2202/1548-923X.1603 
[10] Cant R, Cooper S. Simulation-based learning in nurse education: Systematic review. Journal of Advanced Nursing. 2009 ; 66 : 3-15. PMid:20423432 http://dx.doi.org/10.1111/j.1365-2648.2009.05240.x

[11] Fanning R, Gaba M. The role of debriefing in simulation-based learning. Simulation in Healthcare. 2007; 2: 115-125. PMid:19088616 http://dx.doi.org/10.1097/SIH.0b013e3180315539

[12] Issenberg SB, McGaghie WC, Petrusa ER, Gordon DL, Scalese RJ. Features and uses of high-fidelity medical simulations that lead to effective learning: A BEME systematic review. Medical Teacher. 2005; 27: 10-28. PMid:16147767 http://dx.doi.org/10.1080/01421590500046924

[13] Cant R, Cooper SJ. The benefits of debriefing as formative feedback in nurse education. Australian Journal of Advanced Nursing. 2011; 29: 37-47.

[14] Cantrell MA. The importance of debriefing in clinical simulations. Clinical Simulation in Nursing. 2008 ; 4 : e19-e23. http://dx.doi.org/10.1016/j.ecns.2008.06.006

[15] Disler RT, Rochester SF, Kelly MA, White H, Forber J. Delivering a large cohort simulation - beginning nursing students' experience: A pre-post survey. Journal of Nursing Education and Practice. 2013; 3(12): 133. http://dx.doi.org/10.5430/jnep.v3n12p133

[16] McGaghie W, Issenberg SB, Petrusa ER, Scalese RJ. A critical review of simulation-based medical education research: $2003-09$. Medical Education. 2010; 44: 50-63. PMid:20078756 http://dx.doi.org/10.1111/j.1365-2923.2009.03547.x

[17] Cooper S, Beauchamp A, Bogossian F, Bucknall T, Cant R, DeVries B, et al. Managing patient deterioration: A protocol for enhancing student nurses' competence through web-based simulation and feedback techniques. BMC Nursing. 2012 ; 11 : 18. PMid:23020906 http://dx.doi.org/10.1186/1472-6955-11-18

[18] Bogossian F, Cooper S, Cant R, Beauchamp A, Porter J, Kain V, et al. Undergraduate nursing students' performance in recognising and responding to sudden patient deterioration in high psychological fidelity simulated environments: An Australian multi-centre study. Nurse Education Today. 2013; 35 (5): 691-696. DOI : 10.1016/j.nedt.2013.09.015

[19] Cooper S, Endacott R. Generic qualitative research: A design for qualitative research in emergency care? Emergency Medicine Journal. 2007; 24: 816-819. PMid:18029510 http://dx.doi.org/10.1136/emj.2007.050641

[20] Pink S. Viewing ethnographers’ photographs: interviewing with images. London: Sage, 2007.

[21] Jirojwong S, Johnson M, Welch A. Research methods in nursing and midwifery: Pathways to evidence-based practice. Oxford University Press Australia \& New Zealand: 2011.

[22] Whitehead L. Enhancing the quality of hermeneutic research: Decision trail. Journal of Advanced Nursing. 2004; $45: 512-518$. PMid:15009354 http://dx.doi.org/10.1046/j.1365-2648.2003.02934.x

[23] Helyar S, Griffiths P, Norman IJ. "The damage I could do..."- Qualitative evaluation of a low-fidelity medication administration simulation that generates error as a learning experience for pre-registration nursing students. Journal of Nursing Education and Practice. 2014; 4: 11-19.

[24] Shors TJ. Learning during stressful times. Learning \& Memory. 2004; 11(2): 137-144. PMid:15054128 http://dx.doi.org/10.1101/lm.66604

[25] AbuAlRub RF. Job stress, job performance, and social support among hospital nurses. Journal of Nursing Scholarship. 2004; 36: 73-78. PMid:15098422 http://dx.doi.org/10.1111/j.1547-5069.2004.04016.x

[26] Lasater K. High-fidelity simulation and the development of clinical judgment: Students' experiences. Journal of Nursing Education. 2007; 46(6): 269-276. PMid:17580739

[27] Bland A, Sutton A. Using simulation to prepare students for their qualified role. Nursing Times. 2006; 102(22): 30-32. PMid:16764383

[28] Linder LA, Pulsipher N. Implementation of simulated learning experiences for baccalaureate pediatric nursing students. Clinical Simulation in Nursing. 2008; 4(3): e41-e47. http://dx.doi.org/10.1016/j.ecns.2008.09.002 